\title{
Inadequacy of Device Shape and/or Size
}

National Cancer Institute

\section{Source}

National Cancer Institute. Inadequacy of Device Shape and/or Size. NCI Thesaurus. Code C62947.

The physical size and/or shape of the device was inadequate with regard to the patient's anatomy. 